\title{
Desain Antena Mikrostrip Bentuk Lingkaran Menggunakan Metode Pencatuan Langsung dan Slot Untuk Antena 5G
}

\author{
Junas Haidi ${ }^{1}$ \\ ${ }^{1}$ Program Studi Teknik Elektro Universitas Bengkulu \\ Bengkulu, Indonesia
}

\begin{abstract}
This paper is designing a circular microstrip antenna using slot method for $5 G$ antenna application that works at $28 \mathrm{GHz}$ resonance frequency. The result of the antenna study is $1.044 \mathrm{GHz}$ bandwidth,return loss value of 36,871 dB, VSWR of 1,0865, $43 \mathrm{Ohm}$ of Impedance and HPBW of 18,20 with $10 \mathrm{dBi}$ main lobe. The slot method used in the design of the antenna in this study serves to widen the bandwidth and reduce the return loss of the antenna. Based on antenna parameters obtained during the antenna design and simulation, the design of antennas made for $5 G$ applications at $28 \mathrm{GHz}$ frequency has met the standard of the antenna. Thus, the design results that have been done can be made or fabricated to be used as a $5 G$ antenna.
\end{abstract}

Abstrak - Paper ini adalah merancang antena mikrostrip bentuk lingkaran dengan menggunakan metode slot untuk aplikasi antena 5G yang bekerja pada frekuensi resonansi $28 \mathrm{GHz}$. Dari hasil penelitian antena yang didesain didapatkan lebar bandwidth $1,044 \mathrm{GHz}$, nilai return loss $-36,871 \mathrm{~dB}$, VSWR 1,0865, Impedansi 43 Ohm dan HPBW $18,2^{0}$ dengan pancaran utama $10 \mathrm{dBi}$. Metode slot yang digunakan dalam perancangan antena pada penelitian ini berfungsi untuk melebarkan bandwidth dan memperkecil nilai return loss antena. Berdasarkan parameter antena yang didapat saat perancangan dan simulasi antena, maka perancangan antena yang dibuat bentuk lingkaran untuk apalikasi $5 \mathrm{G}$ pada frekuensi $28 \mathrm{GHz}$ telah memenuhi standar antena. Dengan demikian hasil perancangan yang telah dilakukan telah bisa dibuat atau dipabrikasi untuk digunakan sebagai antena 5G.

Keywords-Millimeter Wave, Microstrip Antenna, Circular Antenna, 5 G.

\section{PENDAHULUAN}

Perkembangan teknologi didunia sangat cepat terutama dibidang telkomunikasi, dimana perkembangan generasi teknologi ini sangat pesat. Dari perkembangan teknologi mulai dari $1 \mathrm{G}, 2 \mathrm{G}$, $3 \mathrm{G}, 4 \mathrm{G}$ dan yang sedang dipersiapkan saat ini untuk mengganti teknologi $4 \mathrm{G}$ adalah generasi ke 5 atau 5G. Teknologi generasi ke 5 ini untuk mendukung teknologi industri 4.0, dimana sistem industri 4.0 adalah semua mesin terhubung dengan internet (IOT) tentunya dengan hal ini dibutuhkan teknologi telkomunikasi yang sangat canggih atau akses data yang sangat cepat. Untuk menghadapi era penerapan industri 4.0 perlu disiapkan teknologi komunikasi baik itu meggunakan kabel atau nirkabel untuk komunikasi yang akses datanya sangat besar. Untuk menjawab industri 4.0 teknologi telkomunikasi telah menyiapkan teknologi telkomunikasi generasi ke 5 atau yang disebut 5G. kecepatan akses data pada generasi ke 5 ini sangat cepat yaitu $1 \mathrm{GHz}$ atau $1 \mathrm{Gbps}$ jauh lebih cepat dibandingkan generasi ke $4 \mathrm{G}$ dengan akses data hanya $100 \mathrm{MHz}$ atau $100 \mathrm{Mbps}$.

Teknologi telkomunikasi generasi $5 \mathrm{G}$ ini masih dikembangkan didunia untuk menggantikan teknologi 4G, berdasarkan hal ini perlu penelitian terus menerus untuk menyempurnakan teknologi
5G. karena teknologi 5G ini mempunyaki akses data yang sangat cepat, maka dibutuhkan peralatan yang mendukung terutama antena yang harus mempunyaki lebar bandwidth minimal $1 \mathrm{GHz}$. untuk membuat antena yang mempunyaki bandwidth yang lebar, berukuran kecil dan tidak mahal maka sangat cocok digunakan antena mikrostrip untuk aplikasi 5G. banyak sekali penelitian - penelitian yang telah dilakukan untuk membuat antena $5 \mathrm{G}$ dengan menggunakan metode slot [1][2][3][4][5][6]. Antena mikrostrip bentuk lingkaran banyak digunakan dalam penelitian antena mikrostrip, dikarenakan antena bentuk lingkaran ini mempunyaki ukuran yang lebih kecil dibandingkan dengan ukuran antena bentuk lain. Antena mikrostrip bentuk lingkaran mempunyaki nilai retun loss yang sangat baik pada saat desain awal, sehingga perkembangan antena bentuk lingkaran banyak digunakan pada antena mikrostrip[6][7].

Desain antena mikrostrip untuk aplikasi antena 5G yang akan dilakukan berbentuk lingkaran. Teknik pencatuan yang akan didesain menggunakan teknik pencatuan langsung, dengan impedansi inputan $50 \mathrm{Ohm}$ dan antena bekerja pada frekuensi $28 \mathrm{GHz}[8]$. Karena antena $5 \mathrm{G}$ yang diinginkan mempunyaki bandwidth yang sangat 
lebar yaitu lebih dari $1 \mathrm{GHz}$ maka perlu metode metode yang digunakan. Dalam hal ini metode yang digunakan untuk meningkatkan bandwidth dan memperkecil nilai return loss adalah metode slot.

\section{DESAIN ANTENA MIKROSTRIP}

A. Desain Antena Mikrostrip Bentuk Lingkaran.

Langkah pertama desain antena mikrostrip bentuk lingkaran adalah menentukan frekuensi kerja antena, pada desain ini frekuensi kerja antena yang didesain adalah $28 \mathrm{GHz}$. Setelaha frekuensi kerja antena sudah ditentukan maka dilakukan perhitungan jari - jari lingkaran antena mikrostrip dengan menggunakan persamaan 1 dan 2[9]. Setelah didapatkan ukuran jari-jari patch maka dilakukan perhitungan lebar saluran transmisi atau lebar pencatu antena dengan menggunakan persamaan 3[9] . untuk ukuran substrat dan ground menyesuaikan dengan diameter patch antena sehingga tampak ukran yang ideal antara ground, substrat dan patch.

$$
\begin{aligned}
& F=\frac{8,791 x 10^{9}}{f_{r} \sqrt{\varepsilon_{r}}} \\
& r=\frac{F}{\sqrt{1+\frac{2 h}{\pi \varepsilon_{r} F}\left[\ln \left(\frac{\pi F}{2 h}\right)+1,7726\right]}}
\end{aligned}
$$

$W=\frac{2 h}{\pi}\left\{B-1-\ln (2 B-1)+\frac{\varepsilon_{r}-1}{2 \varepsilon_{r}}\left[\ln (B-1)+0,39-\frac{0,61}{\varepsilon_{r}}\right]\right\}(3)$

Material yang digunakan pada desain antena mikrostrip adalah substrat RO 3210 untuk aplikasi 5G dengan frekuensi resonansi $28 \mathrm{Ghz}$. Material substrat RO 3210 mempunyaki kestabilan pada frekuensi tinggi yang sesuai dengan frekuensi yang akan didesain yaitu antena yang $5 \mathrm{G}$ dengan frekuensi $28 \mathrm{GHz}$. Spesefikasi material antena yang digunakan untuk desain antena dapat dilihat pada Table 1.

TABEL 1

SPESIFIKASI SUBSTRAT YANG DIGUNAKAN

\begin{tabular}{|c|c|}
\hline Jenis Substrat & RO 3210 \\
\hline Konstanta Dielektrik Relatif $\left(\varepsilon_{r}\right)$ & 10,8 \\
\hline Dielectric Loss Tangent $(\tan \delta)$ & 0.0027 \\
\hline Ketebalan Substrat $(\mathrm{h})$ & $0,64 \mathrm{~mm}$ \\
\hline
\end{tabular}

Setelah dilakukan perhitungan dengan menggunakan persamaan 1, 2 dan 3 didapatkan jari-jari patch antena adalah 7,0427 $\mathrm{mm}$ dan lebar saluran transmisi atau pencatu adalah $0,503 \mathrm{~mm}$. setelah didapatkan jari - jari patch dan lebar saluran antena mikrostrip maka dapat kita buat bentuk antena yang akan didesain. Bentuk antena dan diameter dari hasil perhitungan dapat dilihat pada Gambar 1.

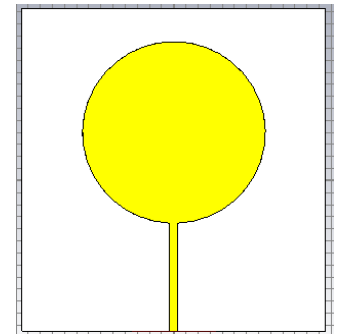

Gambar 1. Bentuk patch antena sesuai dengan teori.

Dari ukuran dan diameter antena yang didapatkan berdasarkan perhitungan menggunakan persamaan 1, 2 dan 3 pada Gambar 1, maka dilakukan simulasi untuk melihat kinerja antena untuk aplikasi 5G dimana setelah dilakukan simulasi dapat dilihat nilai Return loss dan VSWR pada Gambar 2 dan Gambar 3.

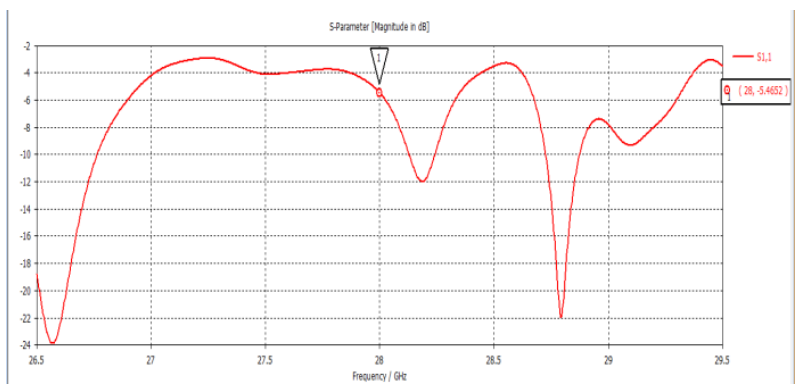

Gambar 2. Grafik return loss antena sebelum diiterasi

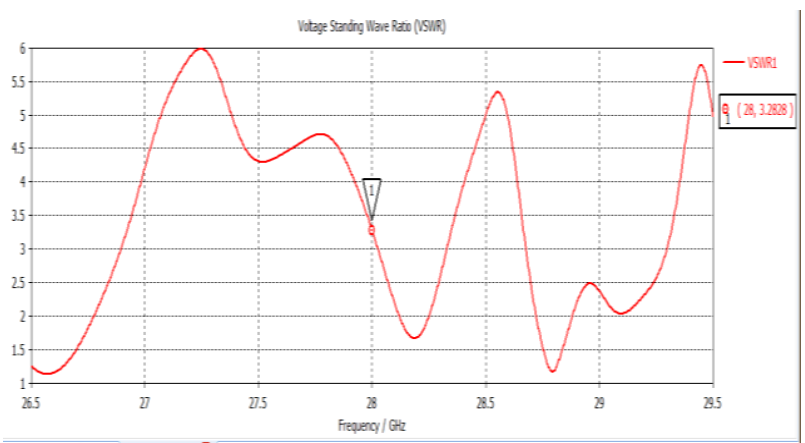

Gambar 3. Grafik VSWR antena sebelum diiterasi

Dari Gambar 2 dan Gambar 3 dapat dilihat nilai dari return loss dan VSWR, dimana nilai return loss pada Gambar grafik 2 adalah $-5,46 \mathrm{~dB}$ pada frekuensi $28 \mathrm{GHz}$ dan dari Gambar 3 nilai VSWR adalah 3,28 pada frekuensi $28 \mathrm{GHz}$. Berdasarkan data yang didapat dari hasil simulasi pada antena pertama ini terlihat bahwa nilai VSWR dan nilai return loss melebihi batas syarat standar antena. Dengan demikian perlu dilakukan iterasi dan metode - metode untuk mendapatkan kinerja antena yang baik sesuai dengan standar dan aplikasi penggunaan antena tersebut. 


\section{B. Metode Penelitian}

Metode penelitian yang digunakan pada desain ini adalah menentukan desain awal antena sesuai dengan teori rumus pada persamaan 1, 2 dan 3. Setelah dapat ukuran awal maka antena mulai didesain seperti pada Gambar 1. Dari bentuk antena yang belum dilakukan iterasi tentu saja belum bisa dijadikan antena dikarenakan nilai VSWR dan return loss nya belum memenuhi standar. Dengan demikian kita perlu melakukan iterasi agar parameter standar antena terpenuhi. Proses iterasi yang dilakukan pada desain antena yang masih tahap awal sebelum menggunakan metode slot adalah memperbesar dan memperkecil jari - jari patch, iterasi panjang saluran pencatu, iterasi panjang dan lebar ground dan substrat. Setelah proses iterasi ini dilakukan, akan didapatkan antena yang bekerja sesuai dengan standar antena yaitu nilai return loss dibawah $-10 \mathrm{~dB}$ dan VSWR kurang dari 2. Biasanya antena yang didesain tanpa menggunakan metode nilai VSWR, Return loss dan bandwidth yang dihasilkan belum optimal.

Karena antena yang didesain ini adalah antena untuk generasi ke 5 atau antena $5 \mathrm{G}$, tentunya membutuhkan bandwidth yang sangat lebar. Untuk mensupport teknologi telkomunikasi yang super cepat perlu dilakukan desain antena menggunakan teknik - teknik tertentu. Dalam penelitian ini akan digunakan metode slot untuk melebarkan bandwidth yang masih sempit dan return loss yang belum optimal. Target dari penelitian ini adalah mendapatkan desain antena yang bekerja difrekuensi tinggi dengan bandwidth antena lebih dari $1 \mathrm{GHz}$. untuk mendapatkan desain antena sesuai dengan target tersebut akan digunakan metode slot untuk mendapatkan lebar bandwidth.

\section{Iterasi desain antena dan pembuatan slot pada patch antena.}

Untuk mendapatkan antena agar bekerja dengan baik maka perlu dilakukan iterasi, sehingga diameter antena pada Gambar 1 akan dilakukan proses iterasi untuk mendapatkan nilai VSWR dan return loss sesuai dengan standar antena yang telah ditetapkan. Dari proses iterasi didapatkan ukuran diameter antena yang dapat dilihat pada Gambar 4 .

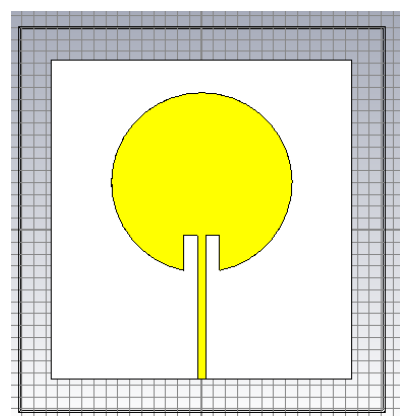

Gambar 4. Antena menggunakan slot saat proses iterasi
Perubahan nilai retun loss dan VSWR saat dilakukan iterasi dan pemberian slot pada patch antena yang didesain. Proses iterasi dilakukan pada jari - jari patch antena, saluran pencatu, lebar dan panjang slot yang dibuat. Dari proses iterasi jari jari patch lingkaran membesar mulai dari 7,042 mm sampai nilai jari - jari patch 7,535 mm, terjadi pergeseran nilai return loss ke arah kiri mulai dari frekuensi 29,4 GHz bergeser kefrekuensi $28 \mathrm{GHz}$. sehingga proses iterasi membesarkan nilai jari jari patch antena dapat menentukan frekuensi kerja antena yang diinginkan yaitu difrekuensi $28 \mathrm{GHz}$. pada saat proses iterasi nilai jari - jari patch antena diperkecil dari 7,042 $\mathrm{mm}$ sampai dengan 6,5 mm terlihat pergeseran nilai retun loss kearah kanan sehingga antena berkera diatas frekuensi $29 \mathrm{GHz}$ dimana tidak sesuai dengan kinerja antena yang diharapkan. Grafik nilai return loss saat proses iterasi jari - jari patch diperkecil dapat dilihat pada Gambar 5 dan Gambar 6.

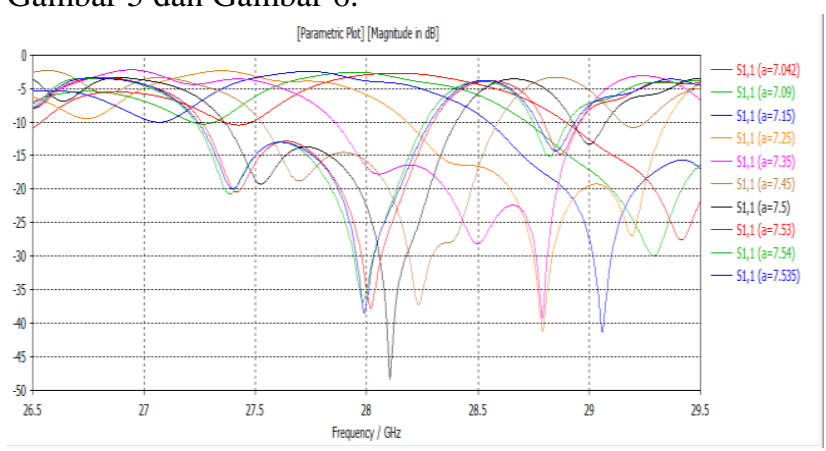

Gambar 5. Grafik return loss iterasi pada jari - jari patch lebih besar dari 7,042 $\mathrm{mm}$.

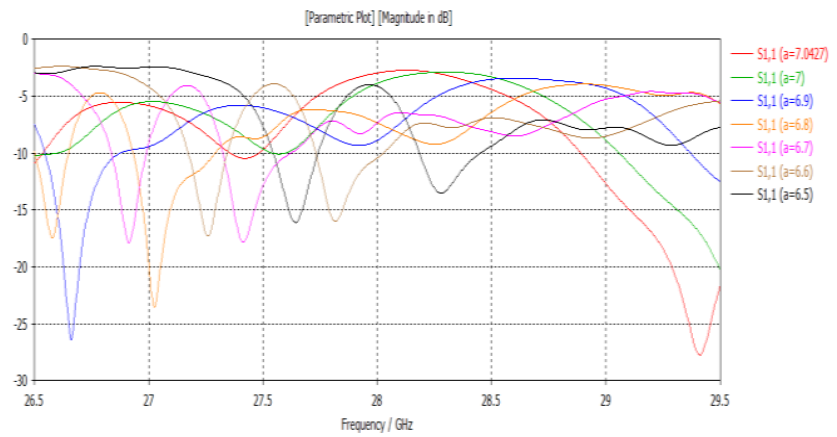

Gambar 6. Grafik return loss iterasi pada jari - jari patch lebih kecil dari 7,042 $\mathrm{mm}$.

Untuk mendapatkan kinerja antena yang lebih baik, maka dilakukan iterasi lebar pecatu atau lebar saluran transmisi. Dari hasil perhitungan menggunakan persamaan 3 didapatkan lebar pencatu langsung sebesar $0,503 \mathrm{~mm}$. pada desain antena ini akan dilakukan proses iterasi dengan lebar saluran pencatu diperbesar sehingga nilai return loss dapat dilihat pada Gambar 7. Dari grafik pada Gambar 7 dapat dilihat bahwa nilai return loss yang paling kecil pada saat lebar saluran pencatu $0.55 \mathrm{~mm}$. dari prosis iterasi lebar saluran pencatu dapat dilihat pengaruh lebar saluran, semakin lebar saluran pencatu maka akan semakin 
besar nilai return loss pada frekuensi $28 \mathrm{GHz}$. sehingga posisi lebar saluran pencatu yang optimal adalah $0,65 \mathrm{~mm}$. Setelah mendapatkan lebar pencatu langsung, maka dilakukan iterasi lebar slot untuk mendapatkan lebar slot yang digunakan pada patch antena. Pemberian slot pada patch antena untuk meningkatkan kinerja antena dimana slot pada patch berfungsi untuk meningkatkan lebar bandwidth dan menurunkan nilai return loss. Untuk melihat pengaruh pemberian slot mulai dari $0 \mathrm{~mm}$ sampai dengan $5 \mathrm{~mm}$ pada antena dapat dilihat pada grafik return loss Gambar 8.
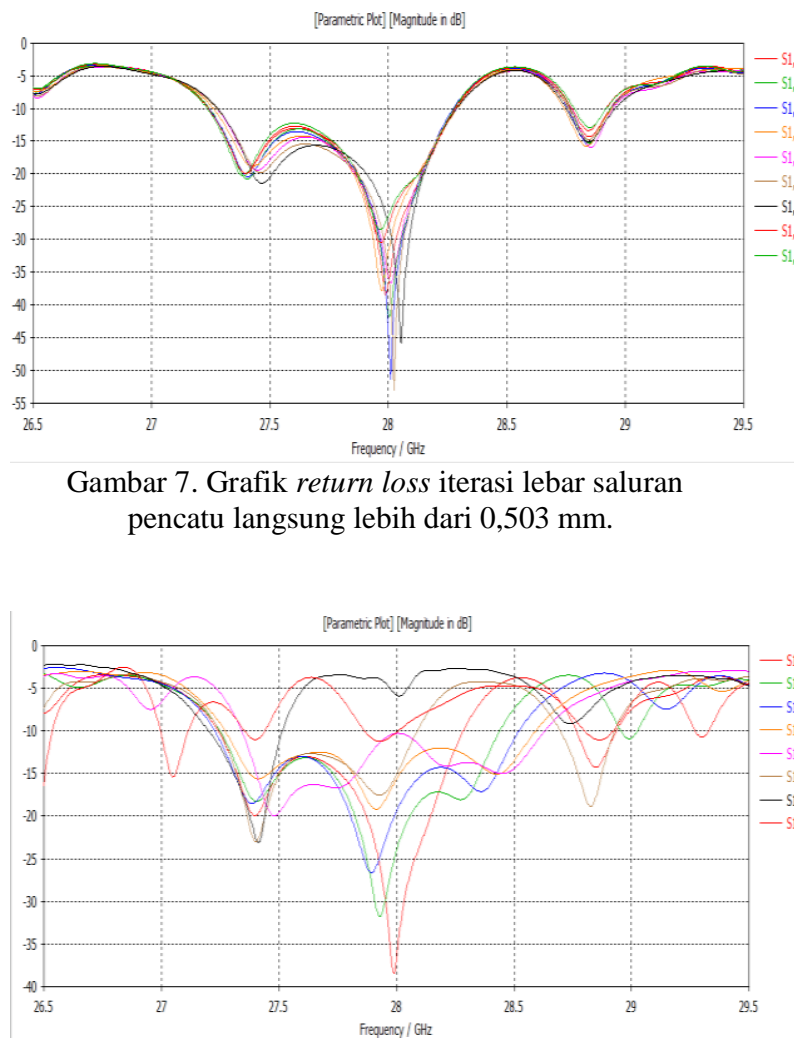

Gambar 8. Grafik return loss iterasi lebar slot dari $0 \mathrm{~mm}$ sampai dengan $5 \mathrm{~mm}$.

Dari Gambar 8 grafik return loss dapat melihat kinerja antena yang didesain, dari gambar grafik tersebut lebar slot yang optimal adalah $3 \mathrm{~mm}$ dengan nilai return loss $-34,9 \mathrm{~dB}$. Dan apabila tidak menggunakan slot maka nilai return loss yang didapat adalah - $6 \mathrm{~dB}$ sehingga antena tersebut tidak bisa bekerja difrekuensi $28 \mathrm{GHz}$.

\section{HASIL DAN PEMBAHASAN}

Dari hasil desain antena menggunakan metode pencatuan langsung dan metode slot didapatkan bentuk dan ukuran antena $5 \mathrm{G}$ yang beroperasi pada frekuensi kerja $28 \mathrm{GHz}$. bentuk dan ukuran antena yang didesain dapat dilihat pada Gambar 9. Dari hasil desain dengan menggunakan pencatuan langsung dan slot, dilakukan proses iterasi maka didapatkan ukuran antena yang optimal pada Tabel 2.

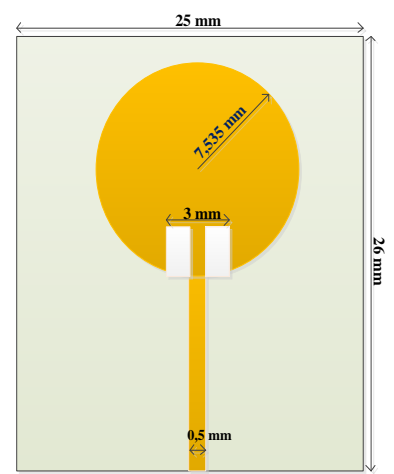

Gambar 9. Hasil desain antena untuk aplikasi 5G

TABEL 2

UKURAN ANTENA BENTUK LINGKARAN YANG DIDESAIN

\begin{tabular}{|c|c|}
\hline Diameter Antena & Ukuran (mm) \\
\hline Jari - jari patch & 7,535 \\
\hline Lebar slot & 3 \\
\hline Lebar saluran pencatu langsung & 0,503 \\
\hline Panjang ground dan substrat & 26,8 \\
\hline Lebar ground dan substrat & 25 \\
\hline
\end{tabular}

Dari desain dan simulasi antena mikrostrip bentuk lingkaran dapat dilihat grafik return loss yang diperlihatkan pada Gambar 10.

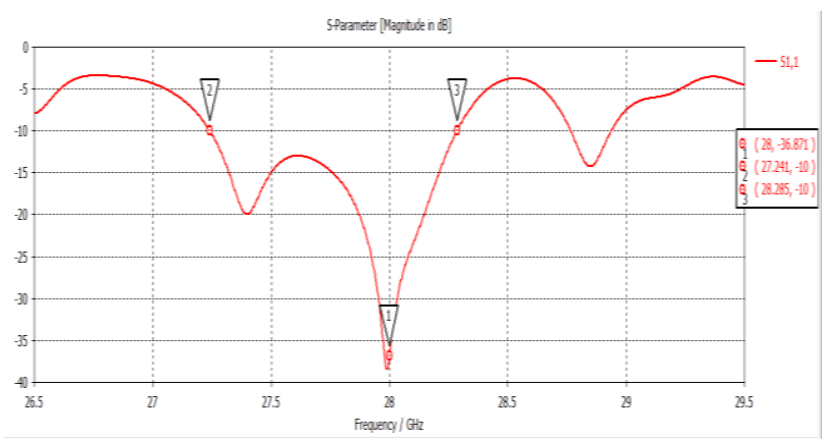

Gambar 10. Grafik return loss dari hasil simulasi desain antena

Dari grafik reurn loss hasil simulasi didapatkan nilai return loss pada frekuensi $28 \mathrm{GHz}$ sebesar $-36,871 \mathrm{~dB}$, frekuensi bawah $27,241 \mathrm{GHz}$ dan frekuensi atas sebesar $28,285 \mathrm{GHz}$ dengan nilai masing - masing return loss sebesar $-10 \mathrm{~dB}$. Setelah didapatkan frekuensi batas bawah dan frekuensi batas atas maka nilai bandwidth yang dihasilkan oleh antena adalah sebesar 1,044 GHz. berdasarkan data yang didapat dari grafik return loss maka desain antena yang dilakukan telah memenuhi standar antena yaitu nilai return loss yang didapat adalah $-36,871 \mathrm{~dB}$ lebih kecil dari standar yang ditetapkan yaitu $-10 \mathrm{~dB}$. Dari nilai return loss yang didapatkan sangat kecil pada frekuensi resonansi $28 \mathrm{GHz}$ ini menunjukan semua energi terpancar dengan sempurna melewati antena bentuk lingkaran. Target dari perancangan antena 
mikrostrip bentuk lingkaran ini adalah nilai bandwidth dari antena lebih lebar dari $1 \mathrm{GHz}$, dimana hasil desain dan simulasi didapatkan lebar bandwidth $1,044 \mathrm{GHz}$ atau telah memenuhi target yang diinginkan. Dengan demikian antena yang didesain telah siap dipabrikasi atau dicetak untuk digunakan sebagai antena 5G. Dari hasil desain dan simulasi antena didapatkan nilai VSWR pada frekuensi resonansi $28 \mathrm{GHz}$ sebesar 1,0865 dan grafik VSWR dapat dilihat pada Gambar 11.

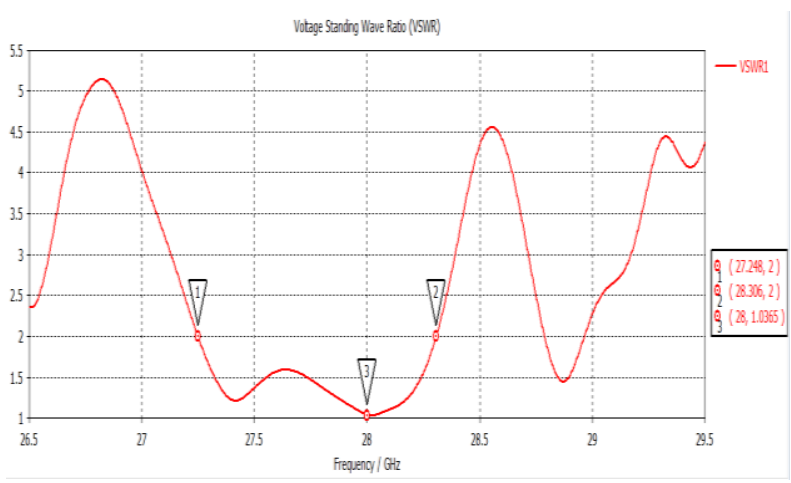

Gambar 11. Grafik return loss dari hasil simulasi desain antena

Dimana antena yang didesain cukup baik karena nilai VSWR memenuhi standar yaitu dibawah 2. Dengan demikian gelombang balik pada antena dengan frekuensi resonansi $28 \mathrm{GHz}$ cukup kecil, sehingga daya balik pada peralatan sangat kecil dan membuat peralatan pemancar atau penerima bisa bekerja dengan baik. Dari hasil simulasi dapat dilihat bentuk smitchart impedansi antena pada Gambar 12. Dimana impedansi input didapatkan adalah 42,99 -j1,49 Ohm atau 43 Ohm. Dari nilai impedansi hasil simulasi saluran transmisi tersebut hampir mendekati $50 \mathrm{Ohm}$, ini memperlihatkan bahwa antena yang didesain sangat matching sehingga antena bekerja sangat optimal di frekuensi $28 \mathrm{GHz}$.

\section{- $26.499998(23,19)$ Ohm - $29.5(10.6,-11.3) \mathrm{Ohm}$} Frequency / GHz

if $28.000000(42.990369,-1.497590)$ Ohn

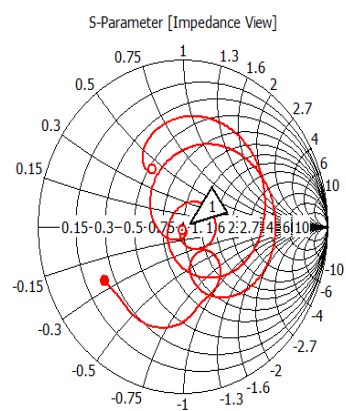

Gambar 12. Smitchart dari hasil simulasi desain antena

Dari hasil simulasi gambar pola radiasi antena dapat dilihat pada Gambar 13 dan Gambar 14. Dari Gambar 13 dapat dilihat nilai HPBW sebesar 18, $2^{0}$ dan dari Gambar 14 terlihat warnah merah pancaran utama atau main lobe sebesar $10 \mathrm{dBi}$. Dari nilai HPBW yang sangat sempit $18,2^{0}$ maka pola radiasi antena yang didesain sangat terarah.

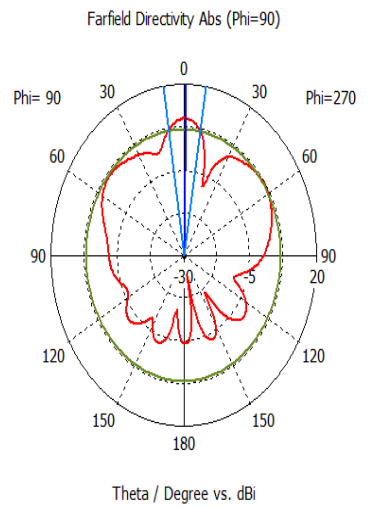

- farfield $(f=28)[1]$

Frequency $=28$

Main lobe magnitude $=\quad 10 \mathrm{~dB}$ Main lobe direction $=1.0 \mathrm{deg}$. Angular width $(3 \mathrm{~dB})=18.2 \mathrm{deg}$ Side lobe level $=-3.2 \mathrm{~dB}$

Gambar 13. Pola radiasi antena 2D

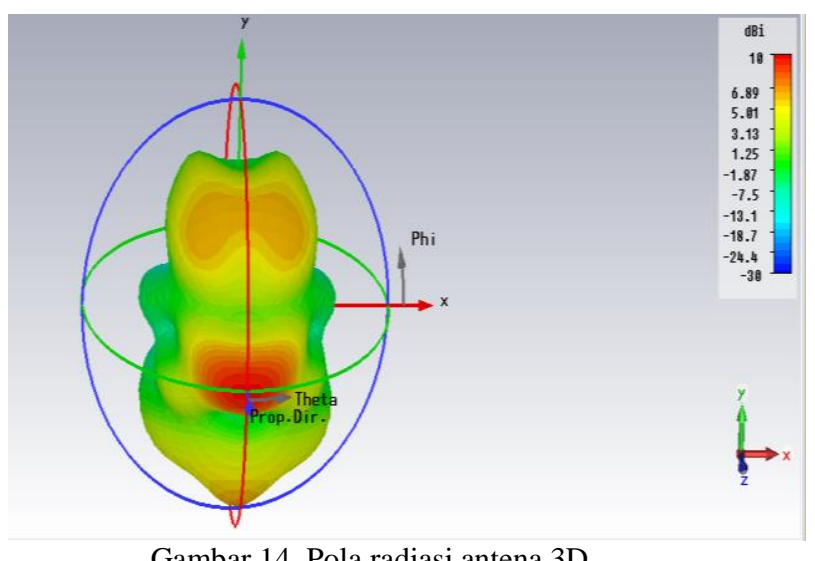

Gambar 14. Pola radiasi antena 3D

\section{KESIMPULAN}

Dari hasil penelitian yang dilakukan pada desain dan simulasi antena mikrostrip bentuk lingkaran dengan menggunakan metode pencatuan langsung dan slot. Didapatkan lebar bandwidth $1,044 \mathrm{GHz}$, nilai return loss $-36,871 \mathrm{~dB}$, VSWR 1,0865, Impedansi $43 \mathrm{Ohm}$ dan HPBW 18, $2^{0}$ dengan pancaran utama $10 \mathrm{dBi}$. Proses iterasi yang dilakukan adalah untuk mendapatkan kinerja antena yang optimal dan metode slot dan pencatuan langsung adalah untuk meningkatkan lebar bandwidth antena dan memperkecil nilai return loss. Berdasarkan data dan perhitungan dari penelitian ini maka antena yang didesain telah sesuai dengan target yang diinginkan, sehingga antena yang didesain bisa dipabrikasi dan telah memenuhi standar antena untuk aplikasi antena 5G pada frekuensi kerja $28 \mathrm{GHz}$.

\section{REFERENSI}

[1] M. M. M. Ali, O. Haraz, S. Alshebeili, and A. Sebak, "Broadband Printed Slot Antenna for the Fifth Generation ( 5G ) Mobile and Wireless Communications," IEEE, pp. 5-6, 2016. 
[2] F. Ahmad, "Design and Analysis of Millimeter Wave Double F Slot Patch Antenna for future $5 \mathrm{G}$ Wireless Communication," in IEEE, 2017, pp. 5-8.

[3] C. Shuai and G. Wang, "Substrateintegrated low-profile unidirectional antenna," IEEE, no. 3, pp. 185-189, 2017.

[4] S. Ho-quang, S. X. Ta, P. Huynh-nguyenbao, K. Nguyen-khac, and C. Dao-ngoc, "Compact Circularly Polarized Slotted SIW Cavity Antenna for 5G Application," in IEEE, 2017, pp. 75-79.

[5] H. J. Zunnurain, Ahmad, "On-Chiip Mounted Millimeter - Wave Dielectric Resonator Antenna," IEEE, pp. 142-144, 2018.

[6] Y. Hendra, Juli, Rio , Rahayu, "Analisis antena mikrostrip array bentuk lingkaran dan persegi panjang menggunakan simulasi untuk aplikasi lte frekuensi $2.3 \mathrm{ghz}$," FTEKNIK, vol. 2, no. 1, pp. 1-14, 2015.

[7] S. B. Husnul Khatim, Setia Bambang, "Studi Dan Antena Mikrostrip MIMO 2X2 Menggunakan Metamaterial Untuk Frekuensi LTE 2.6 GHZ," in Proceeding of engineering, 2015, vol. 2, no. 2, pp. 26622680.

[8] I. F. Costa and A. C. S. Jr, "Dual-Band Antenna Array with Beam Steering for mm-waves 5G Networks," IEEE, 2017.

[9] I. Surjati, Antena mikrostrip konsep dan aplikasinya. jakarta: universitas trisakti, 2010. 